\title{
Interactive Mobile Game for Learning about Sustainablity Education
}

\author{
WaiShiang Cheah, Tay Zhen Wei, Boon Hue kee \\ Faculty of Computer Science \& Information Technology \\ Universiti Malaysia Sarawak, \\ Kota Samarahan, Sarawak, Malaysia \\ wscheah@fit.unimas.my
}

\author{
Fitri Suraya Mohamad \\ Faculty of Cognitive Sciences\& Human Development \\ Universiti Malaysia Sarawak, \\ Kota Samarahan, Sarawak, Malaysia \\ mfitri@fcs.unimas.my
}

\begin{abstract}
Game-based learning is an effective way to engage learners to learn through interactivity afforded by computing technology today. This paper presents an approach to use an interactive mobile game to teach about sustainability issues. The game is created as an interactive mobile application called "LifeTree", and it introduces a new design strategy that uses a bubble analogy throughout the theme in the game. Initial user testing has indicated that the mobile game is found to be interesting and relevant to the learning of environmental issues that challenge the world today.
\end{abstract}

Keywords-component; sustainability education, interactive mobile learning system

\section{INTRODUCTION}

The focus to learn about sustainability has increased significantly in the last few years. Educating the public about sustainability issues is becoming a serious task particularly because of the impact of global development on our environment. To educate today's children and youth, who are widely labeled as "digital natives", because they grew up in a technology-infused environment since birth, the approach to incite learning about issues such as environmental sustainability has to be in tandem with their needs, interests and skills. In line with the growing popularity of mobile gaming today, a project was conducted to design an approach to create a mobile-based game to enable children to learn about issues related to environmental sustainability. The paper details the design and development phases of the mobile game called "LifeTree".

LifeTree is centred on a character named Neo who has a mission to protect all trees in a simulated universe designed for the game. Every stage of the game provides opportunities for players to learn how Neo protects the universe from pollution. Players would learn about natural disasters that are triggered by pollution, for instance haze, tornadoes and so forth. In the game, there are simulations of a tornado created within the game, which will demonstrate the impact of such disasters to human life. Four settings are created within the universe - countryside, urban city, outer space and rural village. Players are required to combat mutants within each setting, by reducing or eliminating causes of pollution that exist in each setting. When any level is won by a player, Neo awards the player with items which encourage healthy living, such as watering cans and seeds to grow various plants.

\section{LITERATURE REVIEW}

Educating users about issues related to sustainability using mobile games is a current interest in the field of computer science. Based on a review done by [4], there are many types of games which are designed to educate users about sustainability, specifically on the environmental issues. The types include action adventure, strategy, simulation and multiplayer online games, puzzles, and augmented reality games. An armchair research on the availability of strategy games on mobile devices only recorded two games since 2012. It signals a need to explore the possibility to develop more games for learning.

In general, sustainability education through digital games is introduced in [5, 6, 7, 8]. An energy conservation digital pet has been introduced to promote energy conservation through various energy conservation strategies [6]. EnvKids is a project that developed to raise the awareness on environmental sustainability among primary school children. It provides the virtual experimental as well as education digital games to the children [7]. Pervasive games have been introduced to promote the sustainability knowledge through social interaction and physical interaction. In the system, player is able to take action to improve their live based on the sustainability knowledge.

They are variety of factors that need to be considered when developing a sustainability education game [5]. Some of the factors like fun, gameplay, interface, the existence of tutorial and sandbox, the immersion, the expected regression, circle of learning, feedback and control, narration rule and goal, fantasy and curiosity, challenge and mystery [5].

We review the current works on sustainability education through digital games-based learning. It is interested to know that digital games based learning is not replacing the conventional teaching method but it is introduced to complement or enhance the existing education practice [7]. From the review, we can conclude that the development of mobile games for sustainability learning is not much address and worth to explore as reported in the following description. 